This is an author generated post-print of the article:

Gama, C., Monteiro, A., Pio, C., Miranda, A.I., Baldasano, J.M., Tchepel, O., 2018. Temporal patterns and trends of particulate matter over Portugal: a long-term analysis of background concentrations. Air Quality, Atmosphere and Health 11, 397-407.

The final publication is available on http://dx.doi.org/10.1007/s11869-018-0546-8 


\title{
Temporal patterns and trends of particulate matter over Portugal: a long-term analysis of background concentrations
}

\author{
Carla Gama ${ }^{\mathrm{a}, *}$, Alexandra Monteiro ${ }^{\mathrm{a}}$, Casimiro Pio $^{\mathrm{a}}$, Ana Isabel Miranda ${ }^{\mathrm{a}}$, José María \\ Baldasano $^{\mathrm{b}}$, Oxana Tchepel ${ }^{\mathrm{c}}$ \\ ${ }^{a}$ Department of Environment and Planning, CESAM, University of Aveiro, 3810-193 Aveiro, Portugal \\ ${ }^{b}$ Environmental Modeling Laboratory, Technical University of Catalonia, 08034 Barcelona, Spain \\ ${ }^{c}$ Department of Civil Engineering, CITTA, University of Coimbra, 3030-788 Coimbra, Portugal
}

\begin{abstract}
Air quality management regarding PM concentrations in the atmosphere is a complex problem to tackle. In this paper, we aim to characterize the temporal patterns and trends of aerosol background levels over Portugal. Hourly data from the national air quality monitoring network, gathered from 2007 to 2016, is analysed using statistical methods. Data from 20 monitoring stations was processed to prepare datasets with different time scales, and results were grouped by their type of surrounding area (urban, suburban or rural). Urban and suburban background sites are characterized by strong seasonal patterns, with higher monthly mean concentrations in winter than in summer. In contrast, rural background PM10 concentrations are highest during August and September. This study suggests that urban background concentrations are significantly influenced by anthropogenic non-combustion sources, which contribute to the coarser aerosol fraction (PMc). PMc is about $3 \mu \mathrm{g} \mathrm{m}^{-3}$ higher during week-days than during Sundays, at urban sites. However, there is no clear relationship between the value of the PM2.5/PMc ratio and the type of monitoring station. During the 10-year period of study, a decrease of $1.83 \% /$ year, $3.58 \% /$ year and $4.89 \% /$ year was registered in PM10 concentrations at Portuguese rural, urban and suburban areas, respectively. Despite the higher decrease at suburban monitoring stations, those sites present the highest 10year mean PM10 concentrations. This work provides an import insight on temporal variations of PM10, PM2.5 and PMc concentrations over Portugal and summarizes trends through the last decade, contributing to the discussion on sources and processes influencing those concentrations.
\end{abstract}

Keywords: particulate matter, Portugal, seasonal patterns, air quality, PM2.5/PMc ratio

\footnotetext{
*Corresponding author

Email address: carlagama@ua.pt (Carla Gama)
} 


\section{Introduction}

Atmospheric aerosols affect air quality and climate, their impacts have been evidenced in many studies across urban, regional, and global scales (Calvo et al. 2013; Fuzzi et al. 2015). Furthermore, exposure to atmospheric aerosols may affect human health (WHO-OCDE 2015). In the past decades, many studies highlighted the role of ambient airborne particulate matter (PM) as an important environmental pollutant for cardiopulmonary diseases and lung cancer (e.g. LópezVillarrubia et al. 2016; Valavanidis et al. 2008).

In addition to primary emission sources, PM concentrations can be significantly influenced by secondary aerosol formation in the atmosphere, which is not only dependent on the precursor emissions but also on meteorological conditions and geographical location. Furthermore, in addition to local pollution sources, air quality is affected by long-range transport of air masses that contribute to regional background pollution levels and air pollution episodes. In this context, North African dust outbreaks may influence air quality in Europe, especially on the Mediterranean Basin (Pey et al. 2013). Thus, air quality management regarding PM concentrations in the atmosphere is a complex problem to deal with.

Due to the geographic location of Portugal and the dominant wind regime (Valverde et al. 2015), influenced by the presence of the semi-permanent Azores high-pressure and the Icelandic low-pressure systems over the North Atlantic Ocean, it is expected that, most of the year, transport of maritime air promotes a decrease of anthropogenic and mineral PM concentrations (Almeida et al. 2013). Nevertheless, Portugal has been facing air quality problems, being PM10, together with $\mathrm{O}_{3}$, the main critical pollutants. Furthermore, results from Monteiro et al. (2017b) evidence that human health protection will be even more critical in the future, particularly for PM; in 2050, due to the warmer and dryer conditions and the expected increase of background concentrations, degradation of air quality is expected to occur.

Several studies intend to characterize PM long-term trends in European regions (e.g., Barmpadimos et al. 2012; Cusack et al. 2012; Guerreiro et al. 2014). However, to our knowledge, no study was published focusing on long-term detailed analysis for Portugal. Specifically for Portugal, PM levels were previously characterized by Cruz et al. (2016), throughout a 3-year period only. Other studies focused on the characterization of PM levels and composition over 
specific cities or regions, based on intensive experimental campaigns. PM composition and sources have been documented for Lisbon (Almeida et al. 2006, 2009) and Porto (Custódio et al. 2016; Diapouli et al. 2017).

The aim of this study is to provide a characterization of the aerosol background levels in Portugal, based on the long-term observations of PM10 and PM2.5 concentrations. Background levels or concentrations are pollution levels which are not influenced significantly by any single source, but rather by the integrated contribution from all upwind source areas. This is the first attempt to characterize aerosol over Portugal with such a long record (10 years) of observations and a large number of monitoring stations. The results of this study bring new insights on the temporal patterns and trends of PM levels over Portugal, and also on the distribution between fine and coarse particulate matter.

\section{Methodology}

Surface data from the Portuguese air quality monitoring network (see http://qualar.apambiente.pt/) is used in this paper to characterize PM levels in Portugal. We focus on PM10 and PM2.5 concentrations collected over the last 10 years, more precisely, observations recorded from January 2007 to December 2016. The aerosol coarse fraction, PMc (the size fraction between 2.5 and $10 \mu \mathrm{m}$ ), was estimated through the subtraction of PM2.5 from collocated PM10.

Air quality data is analysed in terms of temporal patterns, long-term trends and legal limit compliances. Temporal patterns (which include daily, weekly and monthly cycles) and long-term trends of concentrations were performed using the OpenAir package for R (Carslaw and Ropkins 2012; Ropkins and Carslaw 2012).

\subsection{Data}

In Portugal, the air quality stations from the national air quality monitoring network are classified by their type of influence (traffic, industrial or background) and the area or environment type: (urban, suburban or rural). Within the scope and aim of the present study, we consider the background influenced sites, e.g., sites which are not influenced significantly by any single source, but rather by the integrated contribution from all upwind source areas. Background sampling points shall, as a general rule, be representative for several square kilometres. Sites from Azores 
and Madeira islands are not included in this characterization.

Data quality objectives for air quality assessment are defined in the EU Directive2008/50/EC (EU 2008) as a percentage of hourly data availability along the year. The minimum percentage of data capture for PM10 and PM2.5 is $90 \%$. Despite the minimum $90 \%$ of data quality objectives, in some cases, measurements from stations with a minimum annual data capture of $75 \%$ are used to achieve data continuation over time. Between 2007 and 2016, we could gather data for 8 rural, 4 suburban and 8 urban sites, distributed along mainland Portugal (see Figure 1, which depicts the 10-year mean concentrations observed in each of the monitoring stations). Details on the location and classification of the stations used can be found in Table 1, together with the information on data completeness relative to the period 2007-2016.

[Table 1 about here.]

[Figure 1 about here.]

Among the selected stations, 13 only measure PM10 and 7 (4 rural and 3 urban) measure both PM10 and PM2.5 concentrations. All the selected monitoring stations are automatic and use the beta attenuation method to measure PM10 and PM2.5 concentrations. This method stands on betaray absorption in a sample captured on filtering material. The difference between the beta-ray absorption of the exposed and non-exposed filtering material, which is proportional to the mass of the captured suspended particle matter, gives the information on its concentration. However, the data cannot always be considered equivalent to the manual gravimetric reference method, which is required in Europe for compliance measurements. Correction procedures are employed to obtain reference equivalent PM10 data series from automatic beta-attenuation monitors. Most of the monitoring stations use the Environnement S.A MP101M dust monitor. FRO and VCO use the Verewa F-701-20 Ambient Air Dust Concentration Monitor, and MVE and TER use the Thermo ESM Andersen ESM FH 62 IR.

\subsection{Methods}

By simply plotting data in different ways, a visual analysis can often provide valuable insights. As such, a comparison of PM concentrations between different locations or monitoring station 
types can reveal for example, information concerning the likely sources.

Hourly measurements from the selected monitoring stations were processed to prepare datasets with different time scales. Moreover, in this analysis, data were grouped according to station type. In the study of PM temporal cycles or patterns, four different plots are produced: (i) day of the week variation, (ii) mean hour of day variation, (iii) a combined hour of day - day of the week plot and (iv) a monthly plot. In these plots, relative to PM10, PM2.5 and PMc concentrations, the mean and the $95 \%$ confidence interval in the mean are depicted, relative to the 10 years data, aggregated by the time scale and the station classifications. The daily cycle of PM concentrations (mean hour of the day variation) is also plotted split by season.

PM10, PM2.5 and PMc long-term temporal trends have been estimated with the Openair's TheilSen function, which quantifies monotonic trends in unit/year, and calculates the associated $\mathrm{p}$ value through bootstrap simulations. Trend is estimated for mean monthly values, and the $95 \%$ confidence interval of the slope is presented. In this analysis, data has been deseasonalized using the seasonal-trend decomposition procedure based on locally weighted scatterplot smoothing, LOESS (Cleveland et al. 1990).

\section{Results and Discussion}

\subsection{Temporal patterns in PM concentrations}

Urban and suburban sites are characterized by higher PM levels in comparison with rural ones (see Figure 1) and exhibit common typical temporal cycles. Figures 2, 3 and 4 show the monthly variability through an average year, the daily variability through an average week and the diurnal variability per average week and per average day of PM10, PM2.5 and PMc concentrations, respectively, observed between 2007 and 2016 and grouped by station type.

[Figure 2 about here.]

[Figure 3 about here.]

[Figure 4 about here.]

In general, during weekdays, urban and suburban sites show a dip in PM10 concentrations during the night (between $00 \mathrm{~h}$ and $07 \mathrm{~h}$ ) which then rise between $07 \mathrm{~h}$ and $10 \mathrm{~h}$, dropping again 
between $10 \mathrm{~h}$ and $14 \mathrm{~h}$. During the afternoon, concentrations increase and the highest peak of the day is achieved between about $20 \mathrm{~h}$ and $23 \mathrm{~h}$. This profile is similar to those found by Harrison et al. (2012) relative to specific UK urban background stations. On Sundays, on the same group of stations, the peak in the early morning is not significant (probably due to the absence of the morning rush-hour traffic) and concentrations reach their minimum values in the beginning of the afternoon (around 14h). They then rise until around 21h, achieving the highest peak of the day, which is, as expected, lower than during week-days.

The combined hour of day - day of the week plot for PM2.5 shows a similar cycle to the PM10 one. Apart from the magnitude of concentrations, the main differences rely on the morning rise of concentrations, which is weaker for PM2.5, and on the differences between week-days and Sundays. The larger difference, between week-days and Sundays, in the magnitude of PM10 concentrations during late evening peaks at urban sites, reflects the importance of coarse particles of anthropogenic origin in Portuguese urban areas. Figure 4 shows that PM coarse fraction is about to $3 \mu \mathrm{g} \mathrm{m}^{-3}$ higher during week-days than during Sundays, at urban sites.

The late evening peak shown in the mean hour of day plots is related with both the daily evolution of the atmospheric boundary layer, which gets thinner during the night, and evening contribution of domestic sources such as heating (Borrego et al. 2010; Gonçalves et al. 2012; Vicente et al. 2015) and cooking (Ots et al. 2016). In addition, according to Harrison et al. (2012), there might exist a contribution of semivolatile material condensing on ambient particles with the lower night-time temperatures. All these causes are more important during winter (due to thinner and more stable boundary layers, more emissions from heating, colder night-time temperatures), which may explain why the intensity of this late evening peak is much stronger during winter (see in Figure 5 the PM10 concentrations daily variability split by_season).

[Figure 5 about here.]

It is at suburban sites that we find the larger differences between seasonally averaged daily cycles. On those stations, during winter, the PM10 late evening peak concentration is $20 \mu \mathrm{g} \mathrm{m}^{-3}$ higher than during summer. This fact suggests a greater use of residential wood combustion in urban suburbs than in city centres, as it happens in other European cities such as London (Fuller et al. 2014) and Berlin (Wagener et al. 2012). It is important to notice that in this analysis we are 
including monitoring stations with different geographical locations (see Figure 1): the 4 suburban monitoring stations are located in the North of Portugal (in Aveiro, Porto and Braga districts), while the other 8 urban monitoring stations, 6 are located in Great Lisbon region (Lisbon and Setúbal districts), one in Coimbra and another one in the Porto district. The different geographical locations might as well contribute to the differences found between PM concentrations measured in urban and suburban groups of stations.

As shown in Figures 2 and 5, rural sites present higher PM10 levels during summer. Most of the rural sites (FPO, FRN, FUN and TER) exhibit pronounced seasonal patterns, with the highest PM10 concentrations observed during August or August/September, when the monthly mean PM10 concentrations are approximately 6 to $8 \mu \mathrm{g} \mathrm{m}^{-3}$ higher than the rest of the year. Cruz et al. (2016), who analysed PM levels in Portugal throughout a 3-year period, attributed this behaviour to the influence of high-altitude mountain stations. In that study, only two monitoring sites (FUN and Douro Norte, a station which is not considered in our characterization due to non-compliance with the data coverage threshold) present the highest PM10 concentrations during summer. The authors relate this with enhancement of secondary particulate formation, arising from photochemical reactions between biogenic VOC compounds and anthropogenic precursors transported from populated coastal areas in the north and the centre of the country.

In our results, we also observe this seasonal trend in low altitude stations (FPO and TER). We agree that the summer maximum might partially result from photochemically driven secondary formation of aerosols (Alves et al. 2001), which is, according to our results, not exclusive to highaltitude stations. Figure 3 also shows an increment in rural PM2.5 concentrations during summer. However, our data analysis suggests, with PMc higher summer levels at rural sites (see Figure 4), that other factors are influencing particulate mass increase in the rural summer atmosphere. Possible reasons which may also contribute for the PM10 summer maximum are local dust emissions from dry soils, the impact of forest fires and long-range transport of African desert dust. In addition, differences in the precipitation patterns between winter and summer may play a huge role in PM concentrations, due to the effect of precipitation scavenging on PM removal from the atmosphere.

Other sites, such as ERM, ERV, FRO, ILH and VCO are characterized by higher average PM10 concentrations during winter. In this group of stations all types of areas are included: urban (ERM), 
suburban (FRO, ILH and VCO) and rural (ERV).

\subsection{Relationship between PM2.5 and PM10 and between PM2.5 andPMc}

PM2.5 and PM10 mass concentrations are correlated and slope values for individual sites range from 0.44 to 0.54 (not shown). These values are lower than the ones calculated by Dingenen et al. (2004) for 11 European sites, using "binned" PM2.5 and PM10 24-h values, which range from 0.57 to 0.89 . Putaud et al. (2010) observed "binned" PM2.5/PM10 ratios between 0.44 and 0.90, in 34 European sites, having not found any clear relationship between PM2.5/PM10 ratio and the type of site or its location in Europe. In our study, we also found no clear relationship between the value of the PM2.5/PM10 ratio and the type of monitoring station. Ratios computed for individual stations range from 0.44 to 0.52 for urban and from 0.44 to 0.54 for rural stations.

Lower PM2.5/PM10 ratios are associated with spatial and temporal conditions where the observed PM levels are dominated by coarse particles. Higher ratios are observed at sites where secondary aerosol sources, which produce fine particles, are predominant (Dingenen et al. 2004), or where fuel combustion is amongst the main sources of particulate matter emissions. The values we calculated for the Portuguese background monitoring stations indicate that we have a significant contribution of the coarser fraction to the total PM10.

In order to analyse with more detail the fine and coarse contribution to the total aerosol mass, Figure 6 shows the daily variability split by season of the PM2.5 and PMc concentrations, at rural and urban background stations. In general, background stations exhibit similar values of PM2.5 and PMc concentrations.

[Figure 6 about here.]

PM2.5 concentrations are higher during winter. The relative contribution of the PM2.5 fraction to the total aerosol mass is on average higher in rural than in urban background stations (mainly during winter). In other words, Portuguese urban background stations show a contribution of anthropogenic emissions to the PMc concentrations. These findings are in accordance with Almeida et al. (2006), which found that during autumn/winter, a predominant fraction of coarse soil dust observed in an urban area (in the outskirts of Lisbon) originates from anthropogenic activities. Most cities with pollution from transport and other combustion sources show a noncombustion source which is mainly attributed to dust re-suspension (from vehicle non-exhaust 
sources, construction activities, soil dust, etc.), which forms part of the coarser fraction PMc.

Figure 7 shows PM2.5 vs. PMc daily mass concentrations for the 7 sites with data from 2007 and 2016. There is no clear relationship between the value of the PM2.5/PMc ratio and the type of monitoring station. At urban sites, the correlation coefficient between fine and coarse particulate matter concentrations indicates a robust relationship between the two variables. This relationship may denote similar PM sources in the atmosphere.

\section{[Figure 7 about here.]}

The rural sites ERV and FUN show lower values of correlation between PM2.5 and PMc. The ERV monitoring station is located $5 \mathrm{~km}$ from the seashore, which means that it might be influenced by sea-spray. However, sea-spray influences mainly large particles (Cesari et al. 2018; Slezakova et al. 2007). The scatter plot of PM2.5 and PMc concentrations shows a large number of points with larger PM2.5 than PMc concentrations, which indicates that sea-spray is not the main contributor in these cases.

\subsection{Long term temporal trends}

In previous sections PM temporal patterns were presented. Here, the trend in PM concentrations through the last decade are discussed. Figure 8 shows the trend in PM2.5, PM10 and PMc concentrations observed at background stations between 2007 and 2016, according to type of station. Statistically significant decreasing trends $(\mathrm{p}<0.001)$ are estimated for the evolution of average PM10 concentrations of each area type (rural background, suburban background and urban background) for the last ten years. The decrease of concentrations is stronger in urban ($0.96 \mu \mathrm{g} \mathrm{m}^{-3} /$ year) and suburban $\left(-1.46 \mu \mathrm{g} \mathrm{m}^{-3} /\right.$ year $)$ stations than in rural ones $\left(-0.35 \mu \mathrm{g} \mathrm{m}^{-3} /\right.$ year $)$; while in 2007 there was a large difference between PM10 levels observed at suburban, urban and rural stations, ten years later, in 2016, the three types of stations measure a similar range of mean concentration values. PM10 concentrations decreased by $1.83 \% /$ year, $3.58 \% /$ year and $4.89 \% /$ year at Portuguese rural, urban and suburban areas, respectively, between 2007 and 2016.

[Figure 8 about here.]

Trend estimates for PM2.5 and PMc concentrations are statistically significant $(\mathrm{p}<0.001)$ at rural background stations and urban background stations, respectively. Over the last decade and 
according to our results, mean PM2.5 concentrations at rural background stations registered a reduction of approximately $-0.25 \mu \mathrm{g} \mathrm{m}^{-3} /$ year. Urban stations registered a huge decrease $(-0.79 \mu \mathrm{g}$ $\mathrm{m}^{-3} /$ year) in the aerosol coarse concentrations, PMc.

The improvement in the air quality might be partly related to the Portuguese economic crisis. Monteiro et al. (2017a) found a relationship between the reductions in energy consumption (registered at transport, industry and residential sectors) and PM10 concentrations in Lisbon and Porto municipalities. Moreover, the economic crises severely affected construction activity within cities, which may positively affect PM10 concentrations due to a reduction in dust production and re-suspension.

\section{Conclusions}

The aerosol background levels in Portugal are analysed based on data gathered from 2007 to 2016. Statistically significant decreasing trends $(p<0.001)$ are observed in the average PM10 concentrations of each area or environment type. The decrease of concentrations is higher in urban $\left(-0.96 \mu \mathrm{g} \mathrm{m}^{-3} /\right.$ year) and suburban $\left(-1.46 \mu \mathrm{g} \mathrm{m}^{-3} /\right.$ year $)$ stations than in rural ones $\left(-0.35 \mu \mathrm{g} \mathrm{m}^{-3} /\right.$ year). Our analysis shows that the main factor contributing to the PM10 decrease in urban areas is the decrease in the PMc concentrations.

PM10 and PM2.5 concentrations are characterized by typical temporal patterns. Throughout the day, concentrations follow the expected patterns with rural sites exhibiting less variability and urban and suburban sites characterized by two main peaks during the day: oneduring the morning, and the largest one late in the evening.

The results of this study point out the importance of coarse particles of anthropogenic origin in Portugal. This conclusion is supported by the larger differences between weekdays and Sundays in PM10 rather than PM2.5. PMc is approximately $3 \mu \mathrm{g} \mathrm{m}^{-3}$ higher during week-days than during Sundays, at urban sites.

It is on suburban sites that the larger differences between the PM10 characteristic daily cycle of each season are found. In this group of stations, the highest daily concentrations (observed at late evening / during the night) during winter are on average $20 \mu \mathrm{g} \mathrm{m}^{-3}$ higher than during summer. PM2.5 concentrations could not be assessed at suburban stations.

The methodology implemented in this work allows to obtain deeper characterization of PM 
levels in Portugal and provides a different view on pollution patterns that was not identified in previous studies. Namely, our results suggest that rural background sites in Portugal reveal higher average PM10 concentrations during summer periods. This finding is relevant in the context of identification of main pollution sources and definition of future pollution abatement strategies. This work provides important insights on temporal variations of PM10, PM2.5 and PMc concentrations over Portugal and summarizes trends during the last decade. Our study contributes to the characterization of background levels of particulate matter and to the ongoing discussion on sources and processes influencing those concentrations.

\section{Aknowledgements}

The authors gratefully acknowledge FCT - Portuguese Foundation for Science and Technology \& FEDER (within the PT2020 Partnership Agreement and Compete 2020) for financing the PhD fellowship of C. Gama (SFRH/BD/87468/2012), the AIRSHIP research project (PTDC/AAGMAA/1581/2014) and CESAM (UID/AMB/50017 - POCI-01-0145-FEDER-007638) associated laboratory. Thanks also are due to the Portuguese Agency for the Environment (APA) and the Regional Coordination and Development Commissions (CCDRs) for their effort in establishing and maintaining the air quality monitoring sites used in this investigation.

\section{References}

Almeida S, Pio C, Freitas M, Reis M, Trancoso M (2006) Source apportionment of atmospheric urban aerosol based on weekdays/weekend variability: evaluation of road re-suspended dust contribution. Atmos Environ 40:20582067. doi:10.1016/j.atmosenv.2005.11.046

Almeida SM, Freitas MC, Repolho C, Dionísio I, Dung HM, Caseiro A, Alves C, Pio CA, Pacheco AMG (2009) Characterizing air particulate matter composition and sources in Lisbon, Portugal. J Radioanal Nucl Chem 281:215-218. doi:10.1007/s10967-009-0113-8

Almeida SM, Silva AI, Freitas MC, Dzung HM, Caseiro A, Pio CA (2013) Impact of Maritime Air Mass Trajectories on the Western European Coast Urban Aerosol. J Toxicol Environ Health A 76:252-262. doi:10.1080/15287394.2013.757201

Alves C, Pio C, Duarte A (2001) Composition of extractable organic matter of air particles from rural and urban Portuguese areas. Atmos Environ 35:5485-5496. doi:10.1016/S1352-2310(01)00243-6 
Barmpadimos I, Keller J, Oderbolz D, Hueglin C, Prévôt ASH (2012) One decade of parallel fine (PM2.5) and coarse (PM10-PM2.5) particulate matter measurements in Europe: trends and variability. Atmos Chem Phys 12:31893203. doi:10.5194/acp-12-3189-2012

Borrego C, Valente J, Carvalho A, Sa E, Lopes M, Miranda AI (2010) Contribution of residential wood combustion to PM10 levels in Portugal. Atmos Environ 44:642-651. doi:10.1016/j.atmosenv.2009.11.020

Calvo A, Alves C, Castro A, Pont V, Vicente A, Fraile R (2013) Research on aerosol sources and chemical composition: Past, current and emerging issues. Atmos Res 120-121:1-28. doi:10.1016/j.atmosres.2012.09.021

Carslaw DC, Ropkins K (2012) openair - An R package for air quality data analysis. Environ Model Softw 27-28:5261. doi:10.1016/j.envsoft.2011.09.008

Cesari D, Benedetto GD, Bonasoni P, Busetto M, Dinoi A, Merico E, Chirizzi D, Cristofanelli P, Donateo A, Grasso F, Marinoni A, Pennetta A, Contini D (2018) Seasonal variability of PM2.5 and PM10 composition and sources in an urban background site in Southern Italy. Sci Total Environ 612:202-213. doi:10.1016/j.scitotenv.2017.08.230

Cleveland RB, Cleveland WS, McRae JE, Terpenning I (1990) STL: A Seasonal-Trend Decomposition Procedure Based on Loess. J Off Stat 6:3-73

Cruz AMJ, Alves C, Gouveia S, Scotto MG, Freitas MdC, Wolterbeek HT (2016) A wavelet-based approach applied to suspended particulate matter time series in Portugal. Air Qual Atmos Health 9:847-859. doi:10.1007/s11869016-0393-4

Cusack M, Alastuey A, Pérez N, Pey J, Querol X (2012) Trends of particulate matter (PM2.5) and chemical composition at a regional background site in the Western Mediterranean over the last nine years (2002-2010). Atmos Chem Phys 12:8341-8357. doi:10.5194/acp-12-8341-2012

Custódio D, Cerqueira M, Alves C, Nunes T, Pio C, Esteves V, Frosini D, Lucarelli F, Querol X (2016) A one-year record of carbonaceous components and major ions in aerosols from an urban kerbside location in Oporto, Portugal. Sci Total Environ 562:822-833. doi:10.1016/j.scitotenv.2016.04.012

Diapouli E, Manousakas MI, Vratolis S, Vasilatou V, Pateraki S, Bairachtari KA, Querol X, Amato F, Alastuey A, Karanasiou AA, Lucarelli F, Nava S, Calzolai G, Gianelle VL, Colombi C, Alves C, Custódio D, Pio C, Spyrou C, Kallos GB, Eleftheriadis K (2017) AIRUSE-LIFE+: estimation of natural source contributions to urban ambient air PM10 and PM2.5 concentrations in southern Europe - implications to compliance with limit values. Atmos Chem Phys 17:3673-3685. doi:10.5194/acp-17-3673-2017

Dingenen RV, Raes F, Putaud JP, Baltensperger U, Charron A, Facchini MC, Decesari S, Fuzzi S, Gehrig R, Hansson HC, Harrison RM, Hüglin C, Jones AM, Laj P, Lorbeer G, Maenhaut W, Palmgren F, Querol X, Rodriguez S, Schneider J, ten Brink H, Tunved P, Tørseth K, Wehner B, Weingartner E, Wiedensohler A, Wåhlin P (2004) A 
European aerosol phenomenology - 1: Physical characteristics of particulate matter at kerbside, urban, rural and background sites in Europe. Atmos Environ 38:2561-2577. doi:10.1016/j.atmosenv.2004.01.040

EU (2008) Directive 2008/50/EC of the European Parliament and of the Council of 21 May 2008 on Ambient Air Quality and Cleaner Air for Europe. OJ L 152, 11.6.2008

Fuller GW, Tremper AH, Baker TD, Yttri KE, Butterfield D (2014) Contribution of wood burning to PM10 in London. Atmos Environ 87:87-94. doi:10.1016/j.atmosenv.2013.12.037

Fuzzi S, Baltensperger U, Carslaw K, Decesari S, Denier van der Gon H, Facchini MC, Fowler D, Koren I, Langford B, Lohmann U, Nemitz E, Pandis S, Riipinen I, Rudich Y, Schaap M, Slowik JG, Spracklen DV, Vignati E, Wild M, Williams M, Gilardoni S (2015) Particulate matter, air quality and climate: lessons learned and future needs. Atmos Chem Phys 15:8217-8299. doi:10.5194/acp-15-8217-2015

Gonçalves C, Alves C, Pio C (2012) Inventory of fine particulate organic compound emissions from residential wood combustion in Portugal. Atmos Environ 50:297-306. doi:10.1016/j.atmosenv.2011.12.013

Guerreiro CBB, Foltescu V, de Leeuw F (2014) Air quality status and trends in Europe. Atmos Environ 98:376-384. doi:10.1016/j.atmosenv.2014.09.017

Harrison RM, Laxen D, Moorcroft S, Laxen K (2012) Processes affecting concentrations of fine particulate matter (PM2.5) in the UK atmosphere. Atmos Environ 46:115-124. doi:10.1016/j.atmosenv.2011.10.028

López-Villarrubia E, Iñiguez C, Costa O, Ballester F (2016) Acute effects of urban air pollution on respiratory emergency hospital admissions in the Canary Islands. Air Qual Atmos Health 9:713-722. doi:10.1007/s11869$015-0382-z$

Monteiro A, Russo M, Gama C, Lopes M, Borrego C (2017a) How economic crisis influence air quality over Portugal (Lisbon and Porto)? Atmos Pollut Res. doi:10.1016/j.apr.2017.11.009

Monteiro A, Sá E, Fernandes A, Gama C, Sorte S, Borrego C, Lopes M, Russo MA (2017b) How healthy will be the air quality in 2050? Air Qual Atmos Health. doi:10.1007/s11869-017-0466-Z

Ots R, Vieno M, Allan JD, Reis S, Nemitz E, Young DE, Coe H, Di Marco C, Detournay A, Mackenzie IA, Green DC, Heal MR (2016) Model simulations of cooking organic aerosol (COA) over the UK using estimates of emissions based on measurements at two sites in London. Atmos Chem Phys 16:13773-13789. doi:10.5194/acp16-13773-2016

Pey J, Querol X, Alastuey A, Forastiere F, Stafoggia M (2013) African dust outbreaks over the Mediterranean Basin during 2001-2011: PM10 concentrations, phenomenology and trends, and its relation with synoptic and mesoscale meteorology. Atmos Chem Phys 13:1395-1410. doi:10.5194/acp-13-1395-2013 
Putaud JP, Dingenen RV, Alastuey A, Bauer H, Birmili W, Cyrys J, Flentje H, Fuzzi S, Gehrig R, Hansson H, Harrison R, Herrmann H, Hitzenberger R, Hüglin C, Jones A, Kasper-Giebl A, Kiss G, Kousa A, Kuhlbusch T, Löschau G, Maenhaut W, Molnar A, Moreno T, Pekkanen J, Perrino C, Pitz M, Puxbaum H, Querol X, Rodriguez S, Salma I, Schwarz J, Smolik J, Schneider J, Spindler G, ten Brink H, Tursic J, Viana M, Wiedensohler A, Raes F (2010) A European aerosol phenomenology - 3: Physical and chemical characteristics of particulate matter from 60 rural, urban, and kerbside sites across Europe. Atmos Environ 44:1308-1320. doi:10.1016/j.atmosenv.2009.12.011

Ropkins K, Carslaw DC (2012) openair - Data Analysis Tools for the Air Quality Community. R J 4:20-29

Slezakova K, Pereira MC, Reis MA, Alvim-Ferraz MC (2007) Influence of traffic emissions on the composition of atmospheric particles of different sizes - Part 1: concentrations and elemental characterization. J Atmos Chem 58:55-68. doi:10.1007/s10874-007-9078-6

Valavanidis A, Fiotakis K, Vlachogianni T (2008) Airborne Particulate Matter and Human Health: Toxicological Assessment and Importance of Size and Composition of Particles for Oxidative Damage and Carcinogenic Mechanisms. J Environ Sci Health C 26:339-362. doi:10.1080/10590500802494538

Valverde V, Pay MT, Baldasano JM (2015) Circulation-type classification derived on a climatic basis to study air quality dynamics over the Iberian Peninsula. Int J Climatol 35:2877-2897. doi:10.1002/joc.4179

Vicente ED, Duarte MA, Calvo AI, Nunes TF, Tarelho L, Alves CA (2015) Emission of carbon monoxide, total hydrocarbons and particulate matter during wood combustion in a stove operating under distinct conditions. Fuel Process Technol 131:182-192. doi:10.1016/j.fuproc.2014.11.021

Wagener S, Langner M, Hansen U, Moriske HJ, Endlicher WR (2012) Spatial and seasonal variations of biogenic tracer compounds in ambient PM10 and PM1 samples in Berlin, Germany. Atmos Environ 47:33-42. doi:10.1016/j.atmosenv.2011.11.044

WHO-OCDE (2015) Economic cost of the health impact of air pollution in Europe: Clean air, health and wealth. Copenhagen: WHO Regional Office for Europe. 


\section{List of Figures}

1 Spatial variation of the PM10 and PM2.5 mean concentrations observed at background stations between 2007 and 2016, according to the monitoring station environmental classification.

2 Hourly, daily and monthly variability of the PM10 concentrations observed at background stations between 2007 and 2016.

3 Hourly, daily and monthly variability of the PM2.5 concentrations observed at background stations between 2007 and 2016.

4 Hourly, daily and monthly variability of the PMc concentrations estimated at background stations between 2007 and 2016.

5 Daily variability split by season of the PM10 concentrations observed at background stations between 2007 and 2016.

6 Daily variability split by season of the PM2.5 and PMc concentrations observed at rural (left plot) and urban (right plot) background stations between 2007 and 2016.

7 Ratio between PM2.5 and PMc concentrations observed at individual background monitoring stations between 2007 and 2016. Rural stations data is represented with green dots in the top panel while data from urban stations is represented by grey dots in the bottom panel.

8 Trends in PM10, PM2.5 and PMc at background stations. The solid black line shows the trend estimate and the dashed lines show the $95 \%$ confidence intervals for the trend based on resampling methods. The overall trend and the $95 \%$ confidence intervals in the slope are shown at the top of each plot. The *** are shown when the trend is significant to the 0.001 level. 

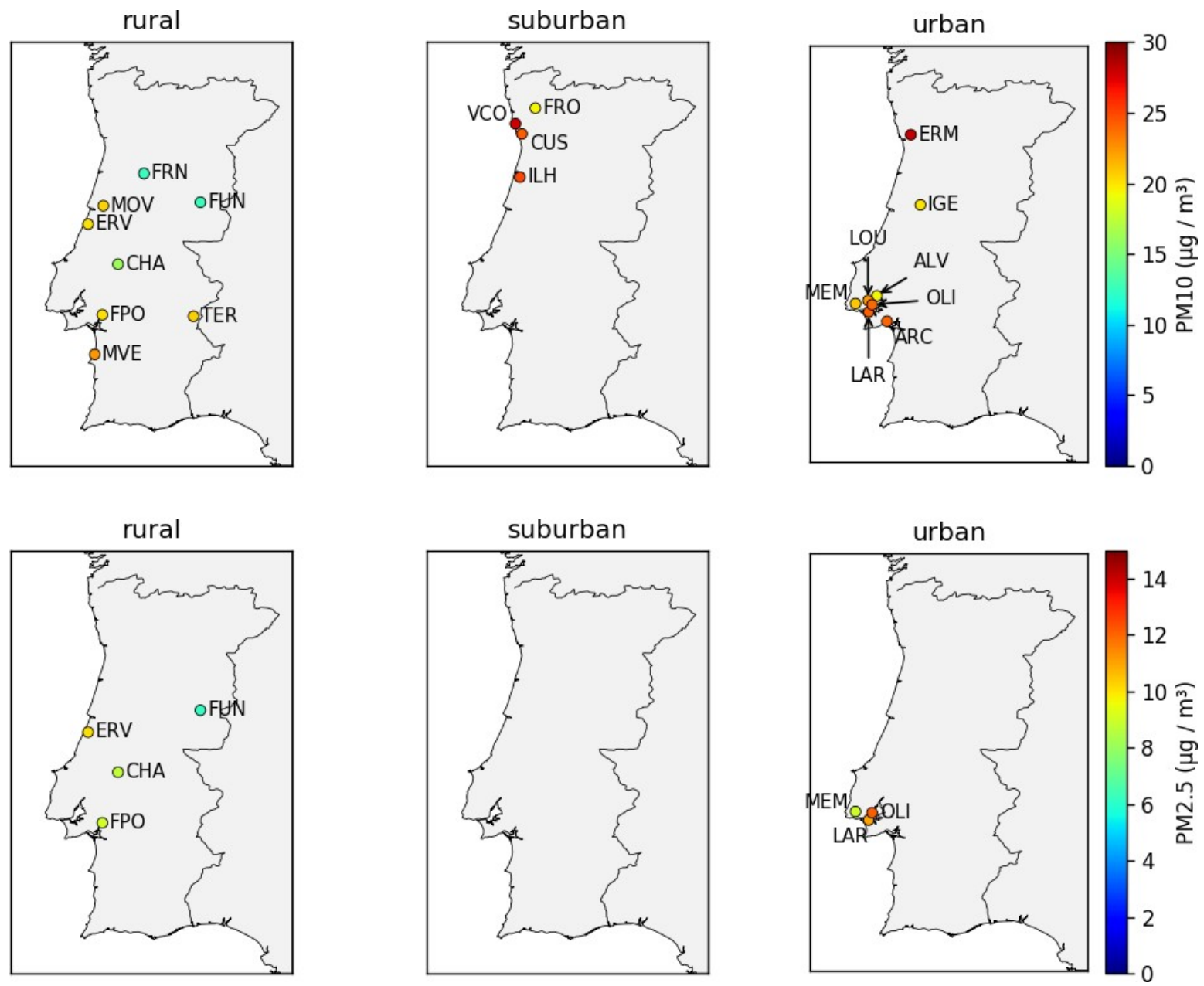

Figure 1: Spatial variation of the PM10 and PM2.5 mean concentrations observed at background stations between 2007 and 2016, according to the monitoring station environmental classification. 


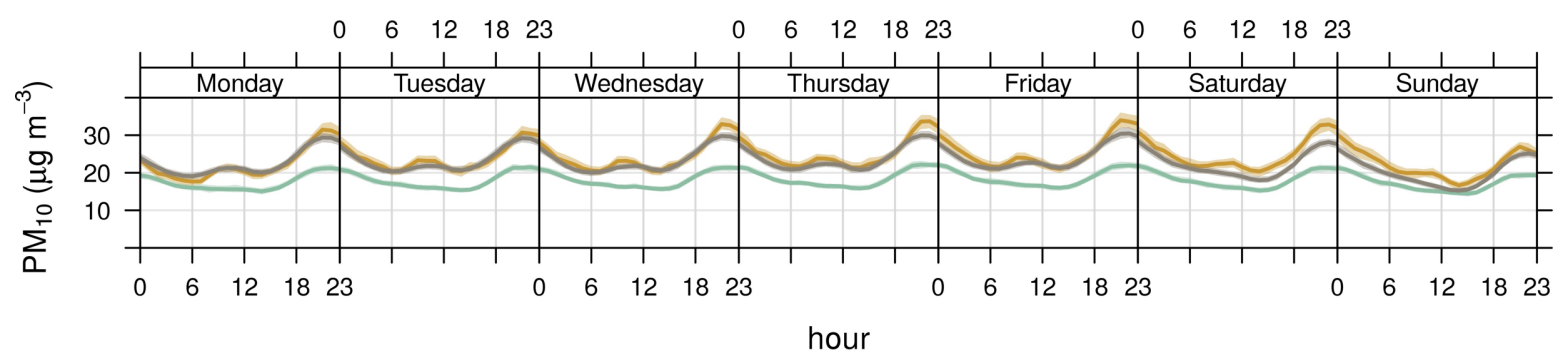

rural

suburban

urban
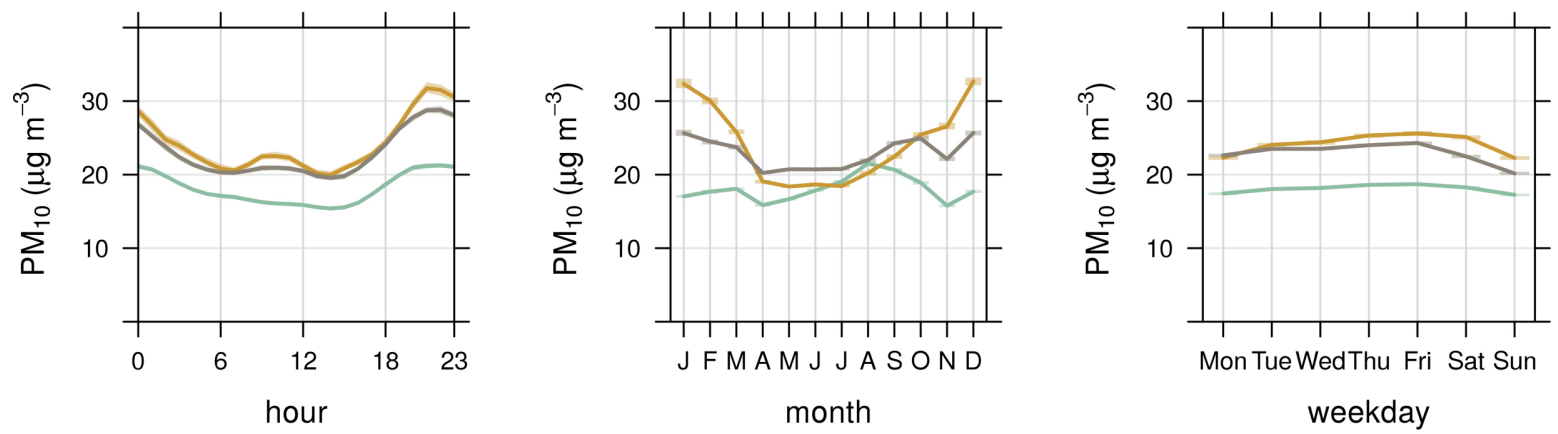

mean and $95 \%$ confidence interval in mean

Figure 2: Hourly, daily and monthly variability of the PM10 concentrations observed at background stations between 2007 and 2016. 


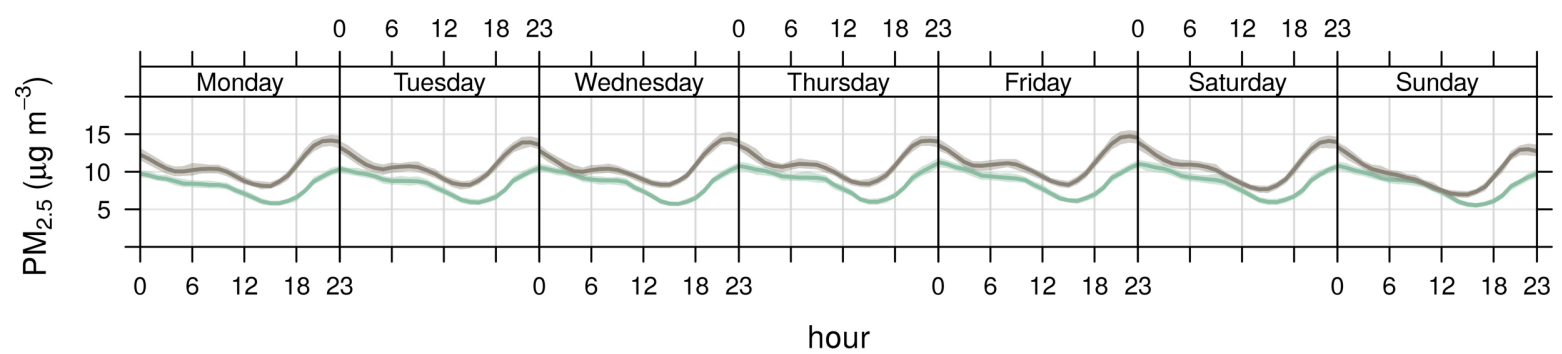

rural urban
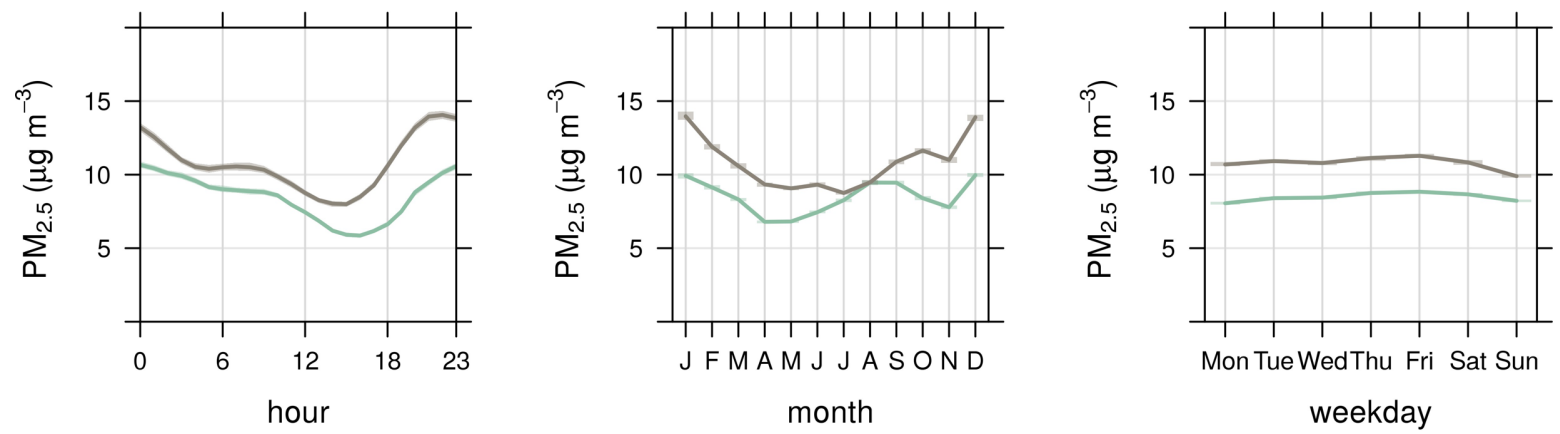

mean and $95 \%$ confidence interval in mean

Figure 3: Hourly, daily and monthly variability of the PM2.5 concentrations observed at background stations between 2007 and 2016. 


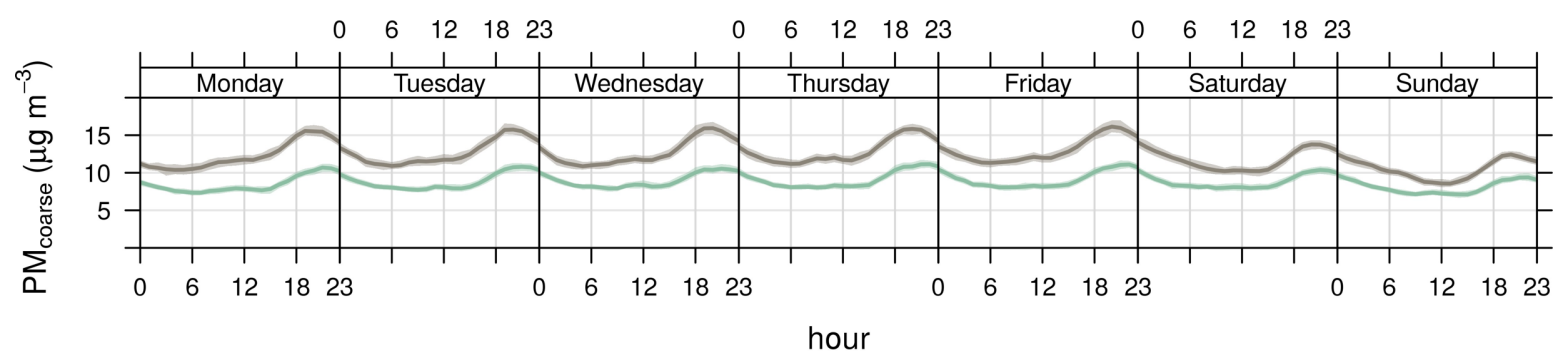

rural urban
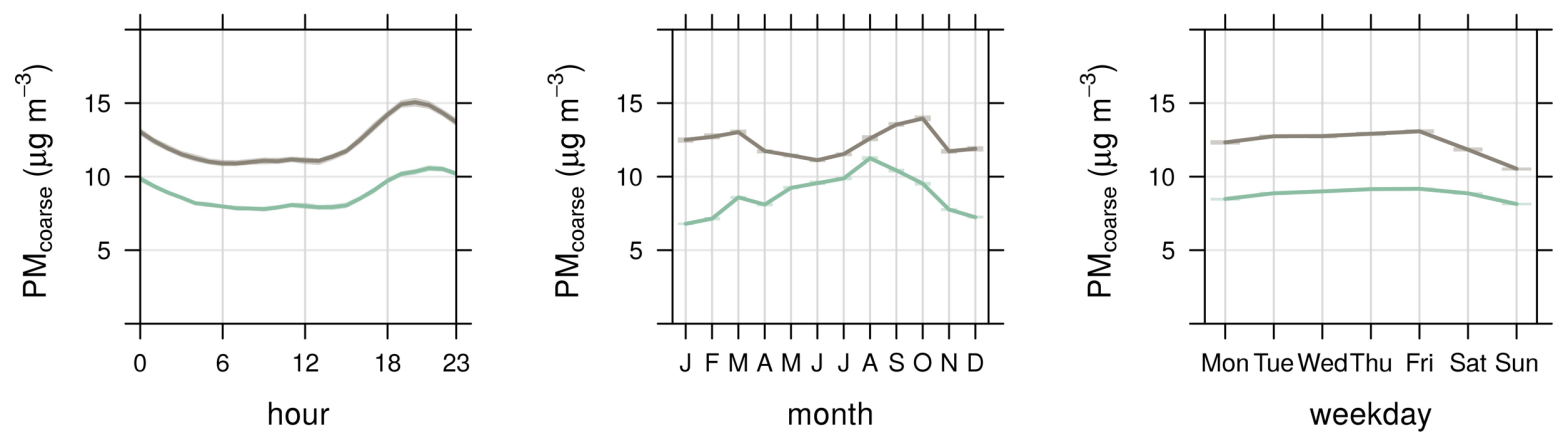

mean and $95 \%$ confidence interval in mean

weekday

Figure 4: Hourly, daily and monthly variability of the PMc concentrations estimated at background stations between 2007 and 2016. 


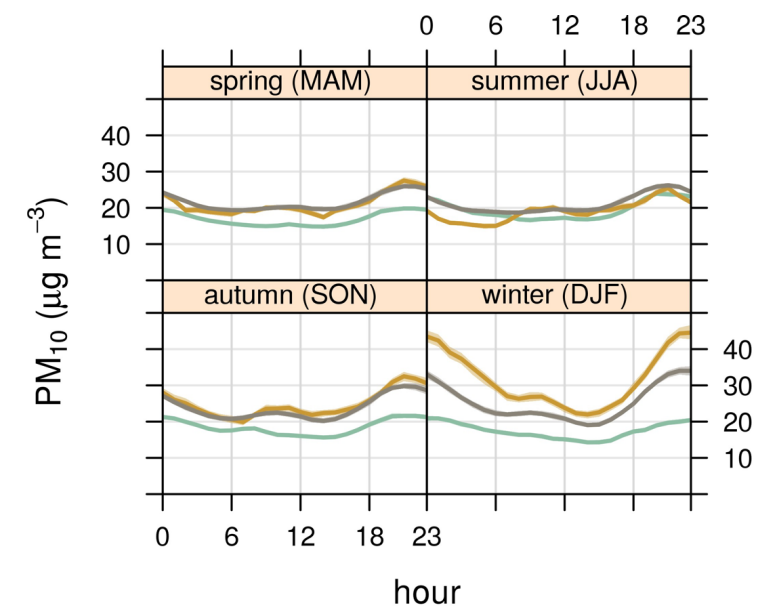

rural suburban $\quad$ urban

mean and $95 \%$ confidence interval in mean

Figure 5: Daily variability split by season of the PM10 concentrations observed at background stations between 2007 and 2016. 


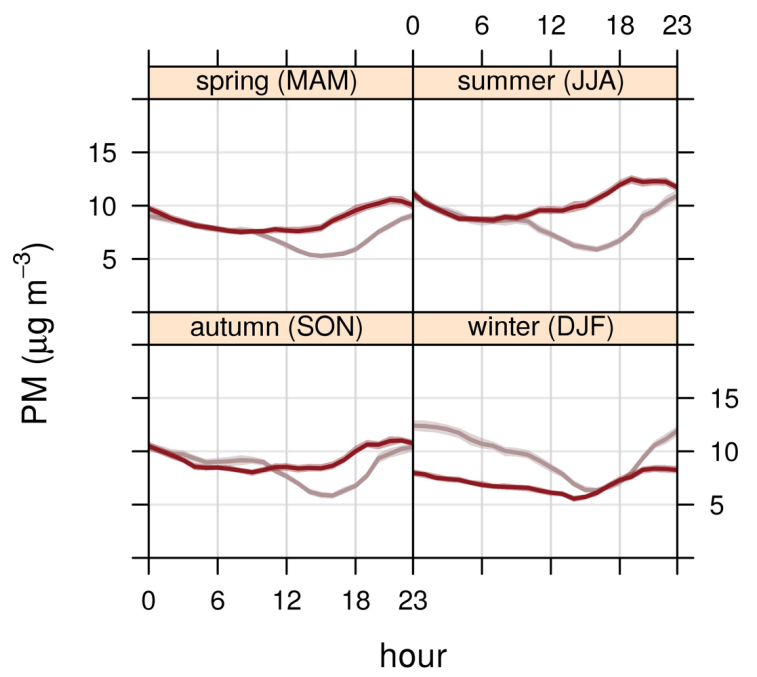

$\mathrm{PM}_{2.5}$

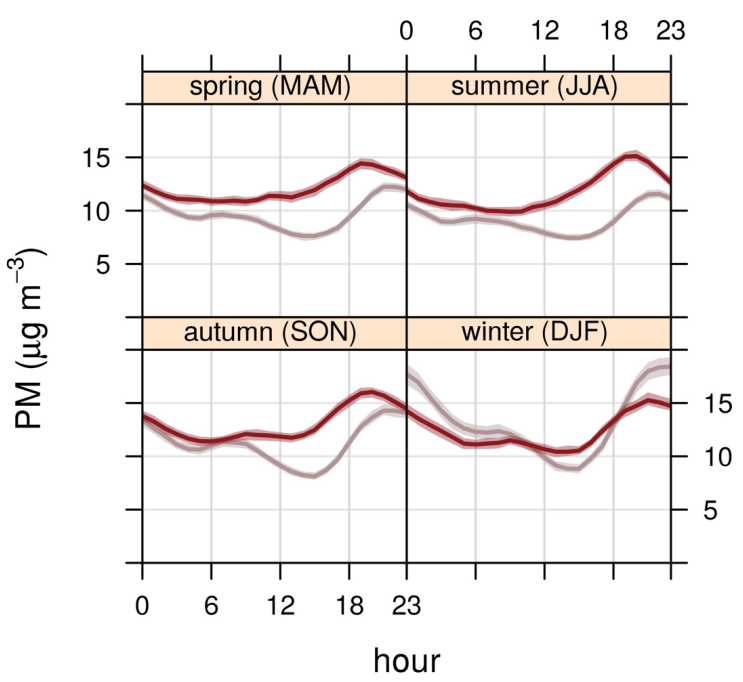

$\mathrm{PM}_{\text {coarse }}$

mean and $95 \%$ confidence interval in mean

Figure 6: Daily variability split by season of the PM2.5 and PMc concentrations observed at rural (left plot) and urban (right plot) background stations between 2007 and 2016. 

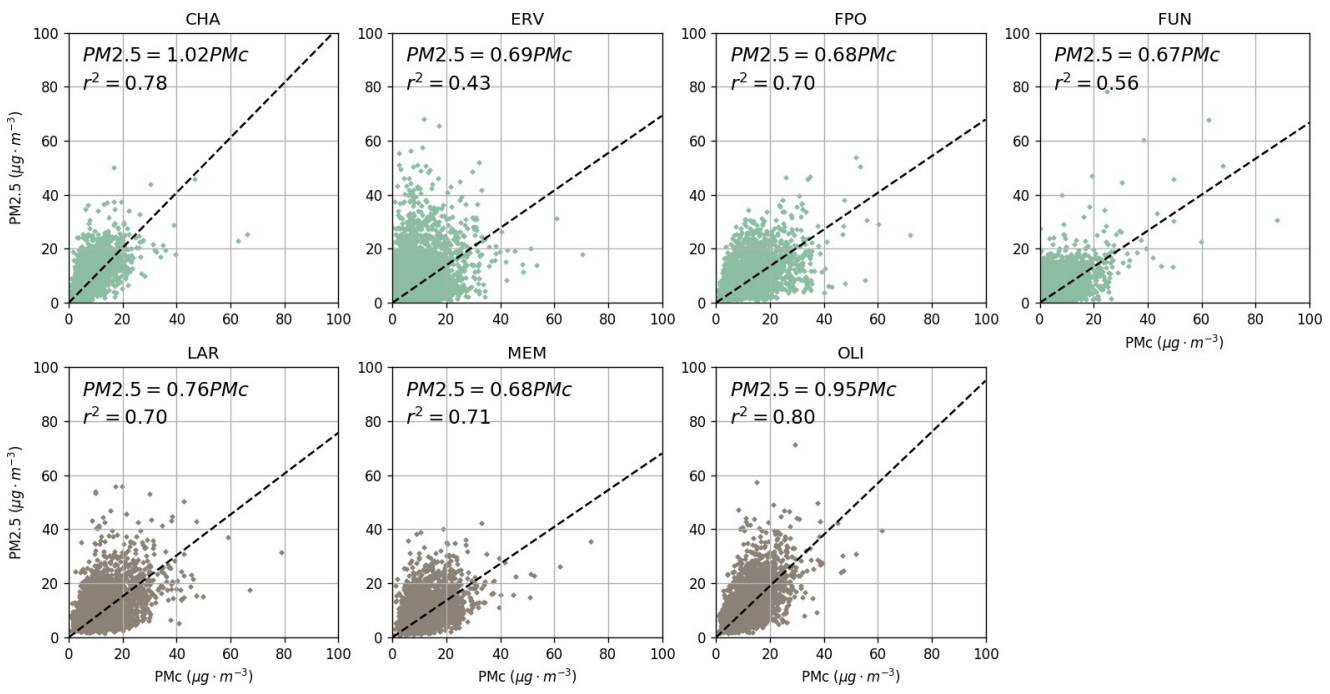

Figure 7: Ratio between PM2.5 and PMc concentrations observed at individual background monitoring stations between 2007 and 2016. Rural stations data is represented with green dots in the top panel while data from urban stations is represented by grey dots in the bottom panel. 


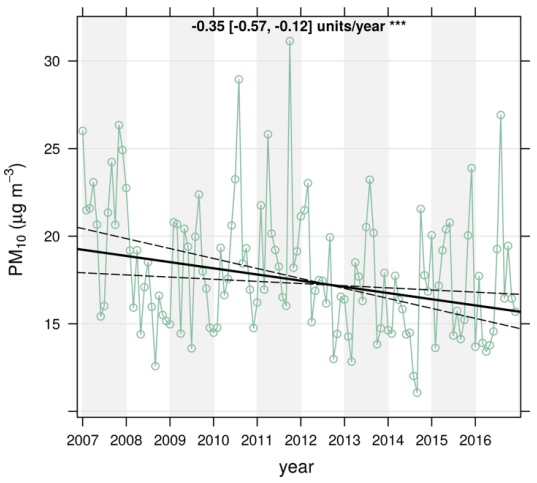

(a) PM10 at rural background stations. (b)

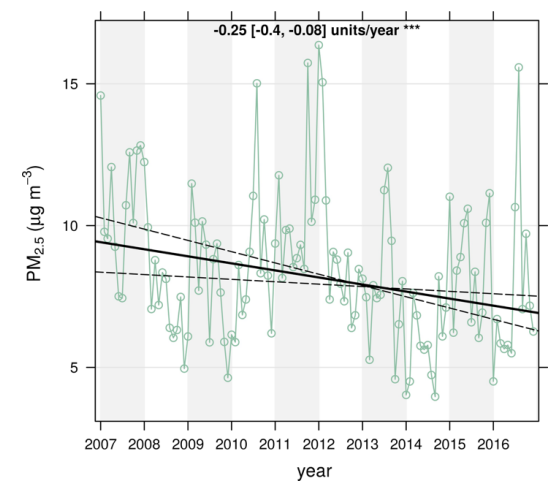

(c) PM2.5 at rural background stations. (d)

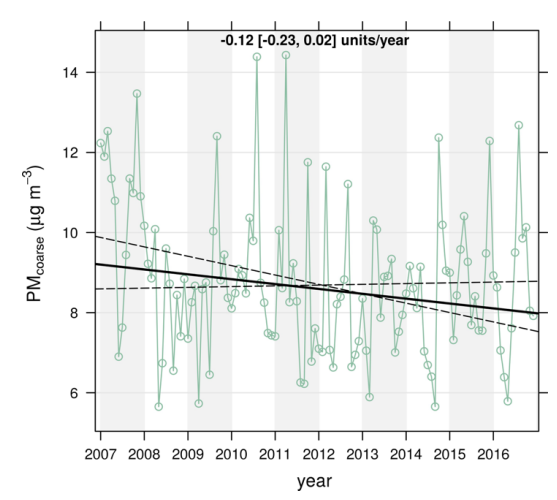

(e) PMc at rural background stations.

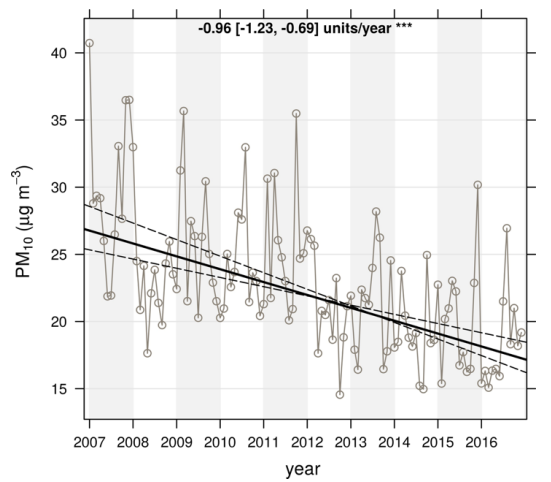

(b) PM10 at urban background stations.

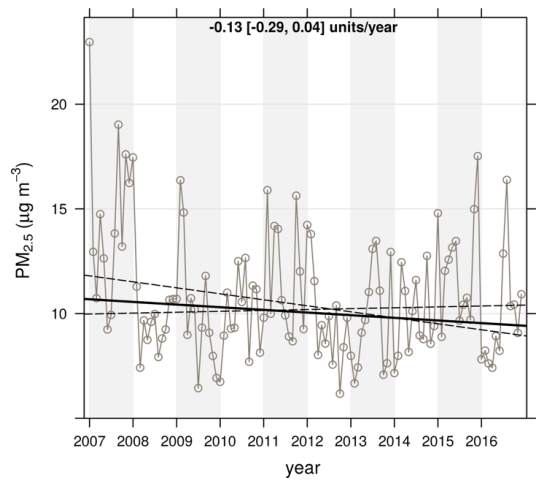

(d) PM2.5 at urban background stations.

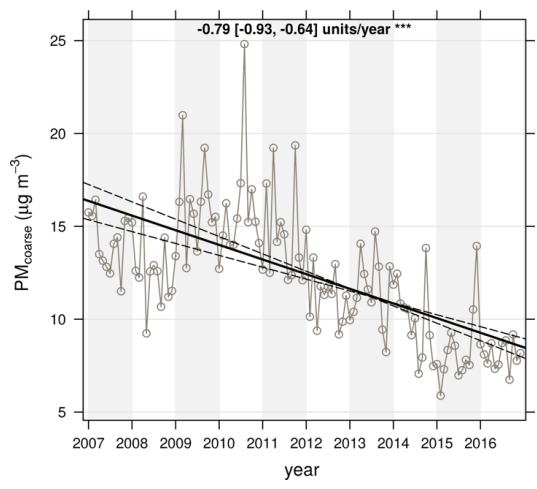

(f) PMc at urban background stations.

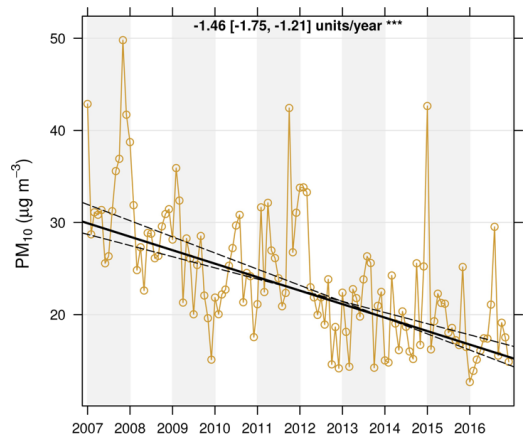

24

(g) PM10 at suburban background stations.

Figure 8: Trends in PM10, PM2.5 and PMc at background stations. The solid black line shows the trend estimate and the dashed lines show the $95 \%$ confidence intervals for the trend based on resampling methods. The overall trend and the $95 \%$ confidence intervals in the slope are shown at the top of each plot. The ${ }^{* * *}$ are shown when the trend is significant to the 0.001 level. 


\section{List of Tables}

1 List of QUALAR background stations with data completeness $>=75 \%$ during the period 2007-2016. Coordinates and surrounding environment type classification are included. 
Table 1: List of QUALAR background stations with data completeness $>=75 \%$ during the period 2007-2016. Coordinates and surrounding environment type classification are included.

\begin{tabular}{lllccccc}
\hline Code & Name & LON & LAT & height $(\mathrm{m})$ & Classification & PM10 data & PM2.5 data \\
\hline ALV & Alverca & -9.040 & 38.896 & 22 & urban & $78.0 \%$ & - \\
ARC & Arcos & -8.894 & 38.529 & 2 & urban & $79.1 \%$ & - \\
CHA & Chamusca & -8.468 & 39.353 & 143 & rural & $95.9 \%$ & $92.2 \%$ \\
CUS & Custóias Matosinhos & -8.645 & 41.201 & 100 & suburban & $82.6 \%$ & - \\
ERM & Ermesinde Valongo & -8.551 & 41.217 & 140 & urban & $83.6 \%$ & - \\
ERV & Ervedeira & -8.893 & 39.922 & 60 & rural & $93.4 \%$ & $92.9 \%$ \\
FPO & Fernando Pó & -8.691 & 38.636 & 57 & rural & $87.3 \%$ & $84.3 \%$ \\
FRN & Fornelo do Monte & -8.100 & 40.640 & 741 & rural & $95.9 \%$ & - \\
FRO & Frossos - Braga & -8.454 & 41.566 & 51 & suburban & $87.7 \%$ & - \\
FUN & Fundão & -7.300 & 40.232 & 473 & rural & $97.2 \%$ & $94.0 \%$ \\
IGE & Inst. Geof. Coimbra & -8.412 & 40.206 & 145 & urban & $93.8 \%$ & - \\
ILH & Ílhavo & -8.672 & 40.588 & 32 & suburban & $92.7 \%$ & - \\
LAR & Laranjeiro & -9.159 & 38.663 & 63 & urban & $94.2 \%$ & $78.1 \%$ \\
LOU & Loures-Centro & -9.166 & 38.828 & 10 & urban & $86.1 \%$ & - \\
MEM & Mem Martins & -9.348 & 38.784 & 173 & urban & $87.3 \%$ & $84.5 \%$ \\
MOV & Montemor-o-Velho & -8.677 & 40.183 & 96 & rural & $87.9 \%$ & - \\
MVE & Monte Velho & -8.799 & 38.076 & 53 & rural & $94.4 \%$ & - \\
OLI & Olivais & -9.109 & 38.768 & 32 & urban & $90.6 \%$ & $87.7 \%$ \\
TER & Terena & -7.398 & 38.616 & 187 & rural & $82.8 \%$ & - \\
VCO & Mindelo V. Conde & -8.736 & 41.345 & 25 & suburban & $82.9 \%$ & - \\
\hline
\end{tabular}

